\title{
Reflets
}

Revue ontaroise d'intervention sociale et communautaire

Janice MacAuley, Les groupes d'entraide pour les parents d'enfants ayant des besoins particuliers, Association canadienne des programmes de ressources pour la famille, 1998.

\section{Madeleine Dubois}

Volume 4, numéro 2, automne 1998

Personnes vivant avec une incapacité

URI : https://id.erudit.org/iderudit/026243ar

DOI : https://doi.org/10.7202/026243ar

Aller au sommaire du numéro

Éditeur(s)

Reflets : Revue ontaroise d'intervention sociale et communautaire

ISSN

1203-4576 (imprimé)

1712-8498 (numérique)

Découvrir la revue

Citer ce compte rendu

Dubois, M. (1998). Compte rendu de [Janice MacAuley, Les groupes d'entraide pour les parents d'enfants ayant des besoins particuliers, Association canadienne des programmes de ressources pour la famille, 1998.] Reflets, 4(2), 239-240. https://doi.org/10.7202/026243ar

Tous droits réservés (C) Reflets : Revue ontaroise d'intervention sociale et communautaire, 1998
Ce document est protégé par la loi sur le droit d'auteur. L'utilisation des services d’Érudit (y compris la reproduction) est assujettie à sa politique d'utilisation que vous pouvez consulter en ligne.

https://apropos.erudit.org/fr/usagers/politique-dutilisation/ 


\section{Les groupes d'entraide pour les parents d'enfants ayant des besoins particuliers}

Janice MacAuley, Association canadienne des programmes de ressources pour la famille (1998)

par

\section{Madeleine Dubois}

École de service social, Université d'Ottawa

Cette trousse offre des renseignements utiles et concis sur les groupes d'entraide aux parents d'enfants ayant des besoins particuliers, ainsi qu'aux professionnels travaillant en collaboration avec ces familles. Quoique le but du document ne soit pas de définir les besoins particuliers dont il est question, ceux-ci peuvent comprendre des incapacités physiques, intellectuelles ou psychologiques ainsi que des maladies chroniques ou incurables.

La trousse comporte quatre fascicules d'une douzaine de pages chacun, traitant des sujets suivants: les deux premiers offrent aux parents des lignes directrices pour l'organisation et la bonne marche de groupes d'entraide parentale, ainsi que pour les groupes d'entraide parentale travaillant avec le corps professionnel; un troisième document intitulé "Soutenir l'entraide parentale", donne des lignes directrices pour le corps professionnel, alors que le dernier comprend des ressources bibliographiques et informatiques ainsi qu'une liste d'associations et de ressources provinciales, pancanadiennes et américaines.

Les sujets abordés traitent notamment des bienfaits de l'entraide et de ses différentes formules, de l'organisation et du maintien de groupes ainsi que d'embûches rencontrées par certains groupes. On aborde aussi la question des liens avec les personnes professionnelles et certaines réticences parfois exprimées par ces dernières face aux groupes d'entraide. Des témoignages de parents et de professionnels apportent des éléments concrets qui servent à illustrer et à appuyer les divers propos. 
Produite par l'Association canadienne des programmes de ressources pour la famille, grâce au soutien de la Section de la santé de l'enfance, de la jeunesse et de la famille, Division de l'enfance et de la jeunesse, Santé Canada, la trousse est disponible au prix de $18 \$$.

Veuillez adresser toute demande à l'Association canadienne des programmes de ressources pour la famille, 101-30 avenue Rosemount, Ottawa (ON) K1Y 1P4 Tél.(613) 728-3307. 